\title{
Support networks in the Middle East \& Malaysia: A qualitative study of Nepali returnee migrants' experiences
}

\author{
Adhikary $\mathrm{P}^{1}$, Teijlingen $\mathrm{E}^{2}$
}

${ }^{1}$ School of Public Health UC Berkeley, USA \& Institute for Social Science and Environmental Research-Nepal ${ }^{2}$ Faculty of Health and Social Sciences, Bournemouth University, UK

\section{ABSTRACT}

Background: There is growing research on Nepali migrant workers, especially on living conditions and occupational health and safety abroad. However, few studied support networks for migrant labourers. Objective of this study is to explore social support and support networks among Nepali migrant workers in the Middle East and Malaysia. Methodology: Study among Nepali men working in the Middle East and Malaysia. Twenty in-depth interviews were conducted and the interviewees were mixed in terms of age, marital status, education, ethnic background and length of stay. Qualitative data were analysed thematically.

Results: The participants found that having (pre-)existing circles of friends in the host countries makes migration easier to migrate, and made their lives easier when establishing themselves abroad.

Conclusion: The assimilation of migrant workers appears to be easier among those who have existing networks in their place of migration. Social Capital Theory helps explain the importance of these networks.

Key words: Interviews; Labour; Migration; Social capital.

DOI: https://doi.org/10.3126/ijosh.v9i2.25998

\section{Introduction}

A $\mathrm{n}$ estimated four million Nepali work abroad in countries other than India, sending over US\$ 7 billion home every year, the equivalent of 650 billion NRs (or 6.5 lakh crore NRs) ${ }^{1}$. The Middle East and Malaysia have been the most attractive destinations for Nepali workers. Limited employment opportunities at home and existing poverty have resulted in increased labour emigration ${ }^{2}$. There are several theories behind labour migrations. Social capital and network theorists ${ }^{3-4}$ suggest that migration happens due to sets of interpersonal ties i.e. bonds of kinship, friendship, and shared community origin that connect migrants, former migrants, and non-migrants to both places of origin

\section{Corresponding Author}

Pratik Adhikary, PhD in Public Health (Bournemouth University, UK)

School of Public Health UC Berkeley, USA \& Institute for

Social Science and Environmental Research-Nepal.

E-mail: adpratik30@gmail.com; pratikiser@outlook.com

Contact Number: + 9779840552042 (cell) and destination. These interpersonal ties or networks among migrants not only lower the costs and risks of migration but also offer support for employment in the destination countries ${ }^{3}$. Thieme highlighted that many poorer migrants only possess social capital, which primarily provides social support, such as emotional and physical support ${ }^{5}$. Migrant workers' theory also reveals that social networks and connections result in exchanges, obligations and shared identities that in turn provide potential support and access to resources ${ }^{6}$ for each individual.

Support network theory might be helpful in explaining the reason for Nepali labour migration to the Middle East and Malaysia. Many Nepali workers have made migration decisions in order to or indeed because of the support of family and friends ${ }^{7}$. This support includes information about jobs, country of work, financial support and motivation. Hence, social capital and network theory is useful to help understand

\section{(c) (1) (8)}

This journal is licensed under a Creative Commons AttributionNon Commercial 4.0 International License. 
labour migration from Nepal to the Middle East and Malaysia; but perhaps less useful to explain the health experiences of Nepali workers in their host country.

In addition to fatalities due to extreme working conditions, naivety to safety at work and individual behaviours, many Nepalese migrant workers also experienced mental health problems and problems including stress, loneliness, hopelessness and frustration in the Middle East and Malaysia ${ }^{8-10}$. This qualitative study explores the role of social support and support networks among Nepali migrant workers in the Middle East and Malaysia.

\section{Methods}

A qualitative study was conducted with Nepali migrants working in the Middle East and Malaysia. The aim was to obtain insight into workers' perspectives on their support networks in the host countries. We distributed invitation letters to male participants who were working at least six months in construction and factories in the Middle East and Malaysia. Men were approached at Tribhuvan International airport, Kathmandu, Nepal on return from their work abroad. A purposive sample of 20 male participants was interviewed for the study.

Fieldwork took place in Nepal between July and September of 2011. The data collection method was semi-structured interviews ${ }^{11}$. After securing written informed consent, a topic guide was used as a prompt for questioning. The first author conducted the face-toface in-depth interviews using a semi-structured guide in venues suitable for the participants ${ }^{10}$. The guide was developed in English and translated into Nepali for all participants. Interviews were recorded using an audio recorder device in order to capture all information provided by the interviewee. The interviews lasted approximately 45 minutes each.

The interviews started with a couple of questions prepared to build rapport with the study participants. These questions focussed on the life experiences as migrant workers and social support they received when they were in the host countries. We continued interviewing participants until no new information is provided from additional interviews (i.e., the point of saturation was reached). Upon completion of each interview and based on the recorded audio the first author developed a detailed transcription that captures all the discussion. These texts and the emerging themes identified during the course of the interviews were confirmed by the research team and issues were addressed. All the interviews were transcribed and prepared for coding and thematic analysis. Finally, data were analyzed by simple thematic analysis.

The study protocol was approved by the ethical committee of the Nepal Health Research Council. Participation in the study was voluntary, all participants gave written informed consent to participate in the study, and confidentiality was guaranteed throughout the research process.

\section{Results}

All of the study participants $(n=20)$ were male migrant workers. The age range of the participants was from 20-49 years, three-quarters $(n=15)$ were married, half of the participants were from privileged (=higher) caste groups (Brahman/Chhetri) and two thirds worked in the Middle East and one third worked in Malaysia (see Table 1).

During data analysis, only one overarching theme about social support and network was identified from the interviews. Some migrant workers spoke about their own experience of support and network at home before migration and others highlighted the support they received at the destination countries.

\section{Encouragement from friends and families:}

Nepalese society has large extended families and family members are often dependent on each other for moral and financial support, help and advice. Consequently, decisions are made for the collective good of the family and family members might be willing to lend or give some 'seed-corn' money for other members to explore a better paying job or business ${ }^{5}$.

Several participants in this study articulated that they received moral and financial support from friends and family members to go abroad with the hope of better overall returns on their original investment. The following expression from one of them exemplifies a family's role in migration:

I completed school up to grade eight. Then I worked in the transportation sector (helping hand), but was not happy with the job, quit it and stayed home. My father encouraged me to go abroad.

(B/C, High edu. Poor health, Malaysia, Age 20, Participant 10) 
Table 1: Socio-demographic characteristics of interviewees

\begin{tabular}{|c|c|c|c|c|c|c|c|c|}
\hline ID & Place & Age & Health & Work & Ethnicity & Education & MS & LS \\
\hline $3^{*}$ & Qatar & 28 & Fair & Poor & $\mathrm{B} / \mathrm{C}$ & $+12 / I . A$ & $\mathrm{M}$ & 2 \\
\hline 4 & Saudi Arabia & 29 & Good & Fair & $\mathrm{B} / \mathrm{C}$ & Prim & $\mathrm{M}$ & 10 \\
\hline 5 & Malaysia & 23 & Good & Good & Dalit & SLC & $\mathrm{M}$ & 4 \\
\hline 6 & Saudi Arabia & 48 & Fair & Fair & Dalit & No & $\mathrm{M}$ & 8 \\
\hline 7 & Saudi Arabia & 49 & Poor & Good & Cha & SLC & $\mathrm{M}$ & 13 \\
\hline 8 & Malaysia & 42 & Fair & Fair & Limbu & SLC & $M$ & 2 \\
\hline 9 & Qatar & 41 & Poor & Poor & Tamang & No & $\mathrm{M}$ & 6 \\
\hline 10 & Malaysia & 20 & Poor & Poor & $\mathrm{B} / \mathrm{C}$ & SLC & $\mathrm{M}$ & 1 \\
\hline 11 & Malaysia & 25 & Poor & Poor & $\mathrm{B} / \mathrm{C}$ & Prim & $\mathrm{M}$ & 3 \\
\hline 12 & Saudi Arabia & 40 & Very Poor & Poor & $\mathrm{B} / \mathrm{C}$ & No & $\mathrm{M}$ & 5 \\
\hline 13 & Qatar & 23 & Good & Good & $\mathrm{B} / \mathrm{C}$ & SLC & UM & 4 \\
\hline 14 & Saudi Arabia & 21 & Very Poor & Poor & Limbu & Prim & UM & 2 \\
\hline 15 & Malaysia & 35 & Very Poor & Poor & $\mathrm{B} / \mathrm{C}$ & SLC & $\mathrm{M}$ & 1 \\
\hline 16 & Malaysia & 25 & Good & Fair & Dalit & Prim & UM & 6 \\
\hline 17 & Malaysia & 38 & Poor & Fair & Tamang & Prim & $\mathrm{M}$ & 2 \\
\hline 18 & Qatar & 40 & Poor & Poor & Dalit & Prim & $M$ & 6 \\
\hline 19 & Qatar & 29 & Good & Good & $\mathrm{B} / \mathrm{C}$ & Prim & $M$ & 3 \\
\hline 20 & Qatar & 27 & Good & Good & $\mathrm{B} / \mathrm{C}$ & SLC & $M$ & 2 \\
\hline 21 & Qatar & 22 & Good & Good & Magar & SLC & UM & 2 \\
\hline 22 & Qatar & 21 & Good & Good & $B / C$ & SLC & UM & 2 \\
\hline
\end{tabular}

Work -Working condition

Ethnic- Ethnicity, B/Cs- Brahmin \& Chhetri, Cha-Chaudhary

Edu.- Education, No Edu- No Education, Prim-Primary Education

SLC- School Leaving Certificate, I.A.+2 or Intermediate level

MS-Marital Status, M=Married, UM=Unmarried

LS-length of stay abroad (in years)

* ID numbers start at 3 as two pilot interviews are not included here.

A construction worker in Saudi Arabia was encouraged by his friends who also lent him money:

I received moral and financial support from my friends. Then I went abroad for work.

(B/C, Low edu. Good health, Middle East, Age 29, Participant 4)

Therefore, several participants experienced positive encouragement from friends and families to go abroad. Friends and families have offered moral and financial encouragement to work abroad, indicating their role as a key motivator in migration decisions.

\section{Network and support}

A number of participants suggested that they have been encouraged to move destination countries by their colleagues and friends. One construction worker in Saudi, for example, had received help from friends and then decided to work abroad. This illustrates the importance of networks making it easier for Nepalese workers to move abroad for work. Socially speaking, existing circles of friends in the host countries are able to teach newcomers about the culture of the country, work environment, wages and information about shopping areas, as this construction worker in Saudi Arabia quoted:

I think Saudi is the best country to work in. My friends who already worked in Saudi encouraged me to apply for work there. They have provided information about the high salary and probability of saving more money than in other countries.

(Chaudhary, High edu. Poor health, Middle East, Age 49, Participant 7)

\section{Discussion}

This qualitative data in the present study revealed that migrating to work in the Middle East and Malaysia among Nepali men is influenced by family and friends and their financial support. One reason interviewees 
often give for working abroad is that a number of migrants are getting emotional, organisational and financial support from friends and families to go abroad. The role of friends and families in-migration has been consistently highlighted as a common theme by researchers such as Boere ${ }^{12}$, Regmi et al. ${ }^{13}$, and Sijapati ${ }^{14}$.

The study highlighted that many migrants migrated abroad with support from friends and families. The theory of social capital offers further insights into the phenomenon of support. Several studies on migrant workers have used social capital as a theoretical foundation ${ }^{13,15}$. The concept of social capital covers 'networks together with shared norms, values, and understandings that facilitate co-operation within or among groups ${ }^{\prime 16}$. Thus it includes financial and social support received (and given) through friendships, relatives and local communities ${ }^{17}$. In our study, part of the explanation for working in the destination countries (Middle East \& Malaysia) is receiving support from friends and family members who had already been to the destination country or were currently working there. One possible reason behind their decision to migrate is that friends in the host countries teach newcomers about the culture of the country, work environment, wages and information about the local market, making them feel more 'at home'.

Social capital and network theorists ${ }^{3-4,18-19}$ suggest that migration happens due to sets of interpersonal ties i.e. bonds of kinship, friendship, and shared community origin that connect migrants, former migrants, and non-migrants to both places of origin and destination. These interpersonal ties or networks among migrants not only lower the costs and risks of migration but also offer support for employment in the destination countries $^{3}$. Social networks and connections result in exchanges, obligations and shared identities that in turn provide potential support and access to resources ${ }^{5}$ for each individual.

Regarding Nepalese migrants, social capital and network theory might be helpful in explaining the reason behind migration to the Middle East and Malaysia. Many Nepalese workers made migration decisions in order to or indeed because of the support of family and friends. This support includes information about jobs, country of work, financial support and motivation. Hence, social capital theory is useful to some extent to understand labour migration from Nepal to the Middle East and Malaysia; but less useful to explain the health experiences of Nepali workers in the host country.

The process of settling in a new society is stressful and that tension may manifest immediately upon the immigrant's arrival. As migrants live and work away from their local community and social network, the lack of social networks and connections coupled with poor working conditions in often unsafe conditions can lead to poor physical health, mental illness, unemployment, family conflicts ${ }^{20-23}$. In the absence of mutual rights, obligations and networks of social interaction, migrants can experience the most antisocial and negative experiences in their host country. Concerning Nepalese migrant workers, Social Capital theory could be helpful in predicting potential mental health problems.

\section{Conclusion}

Social Capital is a useful sociological theory as it provides insight into the role of social networks and connections for migrant workers. Social Capital can help our understanding of Nepali's decisions on going to work abroad and their level of adoption to their work and living conditions due to existing or newly formed networks in the host country.

\section{References}

1. Ministry of Finance. Economic survey: Fiscal Year 2017/18[Internet]. Kathmandu: Ministry of Finance: Government of Nepal; 2018[Accessed on 5th December, 2019]. Available from: https://mof.gov.np/ uploads/document/file/for\%20web_Economic\%20 Survey $\% 202075 \% 20 \mathrm{Full} \% 20 \mathrm{Fi} \quad$ nal\%20for $\% 20$ WEB\%20_20180914091500.pdf.

2. Ministry of Labour and Employment. Labour Migration for Employment. A Status Report for Nepal: 2015/2015-2016/2017[Internet]. Kathmandu: Ministry of Labour and Employment; 2017[Accessed

on Oct 2019]. Available from: https://nepal.iom.int/ jupgrade/images/stories/CoM/LabourMigration_ for_Employment-A_\%20StatusReport_for Nepal_201516201617_Eng.PDF

3. Massey DS, Arango J, Hugo G, Kouaouci A, Pellegrino A, Taylor J E. Theories of international migration: a review and appraisal. Popul. Dev. Rev. 1993;19(3):431-66.

4. Palloni A, Massey DS, Ceballos M, Espinosa K, Spittel M. A test using information on family networks. Am. J. Sociol. 2001;106(5):1262-68. 
5. Thieme S. Social networks and migration: far west Nepalese labour migrants in Delhi, NCCR NorthSouth dialogue Number 15. Bern: NCCR NorthSouth;2007.

6. Bourdieu P. The forms of capital. In: J. Richardson (ed.). Handbook of Theory and Research for the Sociology of Education. New York: Greenwood; 1986:241-58.

7. Adhikary P. Health status of and health risks to male Nepalese migrants in the Middle East and Malaysia. Unpublished PhD Thesis. Bournemouth: Bournemouth University, UK; 2014.

8. Adhikary P, Keen S, van Teijlingen E. Health Issues among Nepalese migrant workers in the Middle East. Health Sci J. 2011;5(3):169-75.

9. Simkhada P, van Teijlingen E, Gurung M, Wasti SP. A survey of health problems of Nepalese female migrant workers in the Middle-East and Malaysia. BMC Int Health Hum Rights. 2018;18:4.

10. Adhikary $P$, Keen S, van Teijlingen E. Workplace accidents among Nepali male workers in the Middle East and Malaysia: A qualitative study. J Immigr Minor Health. 2019; 21(5):1115-22.

11. van Teijlingen E, Simkhada B, Porter M, Simkhada P, Pitchforth E, Bhatta P. Qualitative research and its place in health research in Nepal. KUMJ. 2011;9(4):301-305.

12. Boere A. Low-skilled Indian construction workers in the Gulf, Singapore and Malaysia, Return to India, reintegration \& re-emigration. Unpublished thesis, Utrecht: Utrecht University; 2010.

13. Regmi PR, van Teijlingen E, Mahato P, Aryal N, Jadhav N, Simkhada P, et al. The Health of Nepali Migrants in India: A Qualitative Study of Lifestyles and Risks. Int J Env Res Pub He. 2019;16:3655.

14. Sijapati B. Nepali transmigrants: an examination of transnational ties among Nepali immigrants in the United States. Eur Bull Himal Res. 2009-2010;3536:139-53.

15. Garip F. Social capital and migration: How do similar resources lead to divergent outcomes?. Demography. 2008;45(3):591-17.

16. The Organisation for Economic Co-operation and Development (OECD). The Well-being of Nations: The Role of Human \& Social Capital. Paris: OECD; 2001.

17. Castles S. Understanding global migration: A social transformation perspective. J. Ethn. Migr. Stud. 2010;36(10):1565-86.

18. Fawcett JT. 'Networks, linkages, and migration systems. Int Migr Rev. 1989;23(3):671-80.

19. Lee ES. A Theory of migration. Demography. 1966;3(1):47-57.

20. Aranda MP, Castaneda I, Lee P-J, Sobel E. Stress, social support, and coping as predictors of depressive symptoms: gender differences among Mexician Americians. Soc Work Res. 2001;25(1):3748.

21. Caplan S. Latinos, acculturation, and acculturative stress: a dimensional concept analysis. Policy Politics Nurs Pract. 2007;8(2):93-106.

22. Finch BK, Vega WA. Acculturation stress, social support, and self-rated health among latinos in California. J Immigr Health. 2003;5(3):109-117.

23. Stewart M, Anderson J, Beiser M, Mwakarimba E, Neufeld A, Simich $L$ et al. Multicultural meanings of social support among immigrants and refugees. Int Migr. 2008;46(3):123-59. 